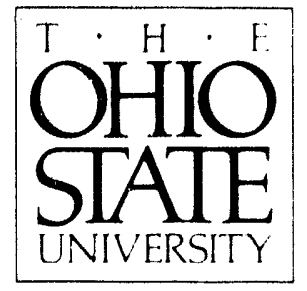

\title{
Reduction of Pumping Energy Losses in District Heating and Cooling Systems
}

\author{
Jacques L. Zakin \\ Department of Chemical Engineering
}

\section{DISCLAIMER}

\begin{abstract}
This report was prepared as an account of work sponsored by an agency of the United States Government. Neither the United States Gnvernment nor any agency thereof, nor any of their employees, makes any warranty, express or implied, or assumes any legal liability or responsibility for the accuracy, completeness, or usefulness of any information, apparatus, product, or process disclosed, or represents that its use would not infringe privately owned rights. Reference herein to any specific commercial product, process, or service by trade name, trademark, manufacturer, or otherwise does not necessarily constitute or imply its endorsement, recommendation, or favoring by the United States Government or any agency thereof. The views and opinions of authors expressed herein do not necessarily state or reflect those of the United States Government or any agency thereof.
\end{abstract}

\section{U.S. Department of Energy}

Washington, D.C. 20585

Grant No. DE-FG01-90CE-26605

Final Report

RF Project No. $768838 / 724395$ 
Table of Contents

Page

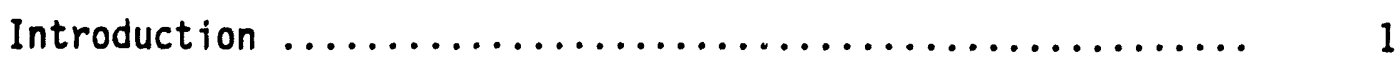

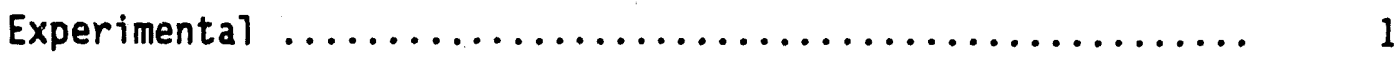

Results and Discussion $\ldots \ldots \ldots \ldots \ldots \ldots \ldots \ldots \ldots \ldots \ldots \ldots \ldots \ldots, 2$

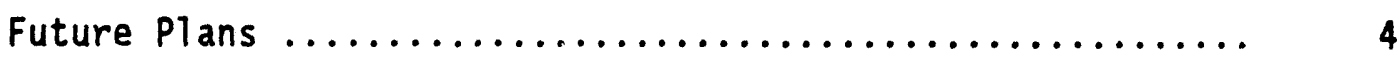

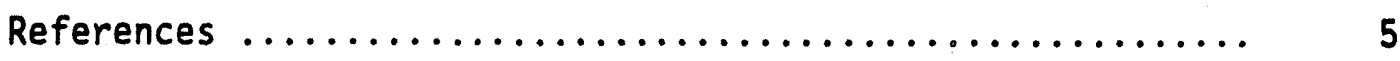

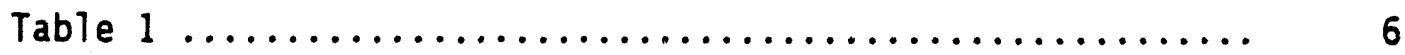

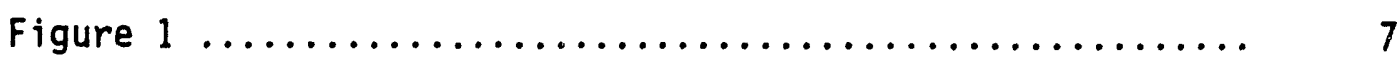

Personnel Involved $\ldots \ldots \ldots \ldots \ldots \ldots \ldots \ldots \ldots \ldots \ldots \ldots \ldots \ldots$ 


\author{
Final Report \\ Department of Energy Project
}

DE-FGO1-90CE-26605

Reduction of Pumping Energy Losses in District Heating and Cooling Systems

Principal Investigator: J.L. Zakin

Dept. of Chemical Engineering

The Ohio State University

140 W. 19th Avenue

Columbus, Ohio 43210

614-292-6986

\title{
Introduction
}

This project was designed to explore the effects of different structures of cationic surfactant drag reducing additives on their. efficiency and on their effective temperature ranges. The goal was to develop surfactant systems that would be useful in the appropriate temperature ranges for district heating systems $\left(50-110^{\circ} \mathrm{C}\right.$ ) and and for district cooling systems $\left(2-20^{\circ} \mathrm{C}\right)$. To this end the chemical compositions of quaternary ammonium salts and of counter-ions were varied. More than twenty different commercial or semi commercial quaterary ammonium salts from U.S. suppliers and two from a German supplier (Hoechst) were tested along with thirty five different counter-ions. In addition, blends of several of each were also tested.

A further object of this project was to check the compatibility of surfactant drag reducers with commercial or semi-commercial corrosion inhibitors in regard to maintaining their drag reducing ability and corrosion inhibiting capability.

\section{Experimental}

The turbulent drag reducing experiments were carried out in two pumping loops which are described in References 1 and 2 . The low temperature loop was suitable for temperatures ranging from $2^{\circ} \mathrm{C}$ to $100^{\circ} \mathrm{C}$ and the high temperature loop from $30^{\circ} \mathrm{C}$ to $150^{\circ} \mathrm{C}$. Their Reynolds number ranges are $\approx$ 15,000 up to $\approx 300,000$. Pressure drop measurements in smooth stainless steel test tubes with diameters of 0.106 and 0.243 inches were made utilizing appropriate entrance and exit kinetic energy loss corrections (3). Turbulent flow test data for deionized water lay close to the von Karman equation predictions and repeatibility was excellent.

Cationic surfactants with aromatic counter-ions are well-suited for these applications as they have reasonable temperature ranges of effectiveness and, while they do lose their drag reducing effectiveness when 
exposed to high shear stresses, they regain their drag reducing effectiveness when they enter a lower shear region.

While a large number of commercial quaternary ammonium salts and counter-ions were examined, the experiments focused on twelve of them and four counter-ions. They are listed in Table 1. Drag reduction of $70 \%$ or more was observed for many of the systems.

\section{Results and Discussion}

A summary of the results follows. More details are given in References $1-7$ and 9 .

A. Effect of Alkyl Chain Length on Upper Temperature Limit

The length of alkyl groups in the quaternary ammonium salts wes varied from 10 to 22 carbons using excess salicylate as counter ion (in a ratio of 5 mmoles $/ 12.5$ mmoles). The upper temperature limit increased continuously from $10^{\circ} \mathrm{C}$ with $C_{10}$ to $120^{\circ} \mathrm{C}$ with $C_{22}(3)$. Thus, proper selection of the alkyl chain length can provide effective drag reduction up to any desired temperature in this range.

B. Effect of Alkyl Chain Structure on Lower Temperature Limit

The presence of unsaturation in the alkyl chain in the quaternary ammonium salt was found to decrease the lower temperature limit for effective drag reduction with no apparent effect on the upper temperature limit (3). Thus, several cationic surfactants containing unsaturated alkyl chains in combination with excess sodium salicylate were effective drag reducers down to $2^{\circ} \mathrm{C}$, the lowest temperature we were able to test (4).

C. Effect of Surfactant Mixtures on Effective Temperature Range for Drag Reduction

A large number of drag reduction runs were carried out over a wide range of temperatures and mixture ratios of ETAC (erucyl trimethyl ammonium chloride) and DTAC (dodecyl trimethyl ammonium chloride) (5). Figure 1 shows the envelope demonstrating the effective temperature range for the mixed surfactant systems studied. The region enveloped by the upper temperature and lower temperature curves are the temperatures where drag reduction greater than $50 \%$ was observed. It was found that when a smal1 quantity of the $C_{12}$ short chain surfactant (DTAC) was mixed with the $C_{22}$

long chain surfactant (ETAC), the lower temperature limit was significantly reduced. For example, as the mole fraction of DTAC in the mixture increased from 0 to 0.15 , the lower temperature limit decreased from 60 to $2^{\circ} \mathrm{C}$, while the upper temperature limit dropped by only $5^{\circ} \mathrm{C}$ to $115^{\circ} \mathrm{C}$. Mixed surfactant with this specific combination has a wide 
effective temperature range, and may be used in operating systems requiring both heating and cooling functions.

When the mole fraction of DTAC was further increased (from 0.33 to $0.625)$, the upper temperature 1 imit dropped rapidly but drag reduction at $2^{\circ} \mathrm{C}$ was still observed.

D. Effect of Head-Group on the Quaternary Ammonium Amine Salt on Effective Temperature Range

The quaternary ammonium amine salts studied were alkyl trimethyl, alkyl methyl bis-hydroxyethyl or alkyl tris-hydroxyethyl amine salts. Thus, the surfactant head group had zero, two or three hydroxyethyl groups. More hydroxyethyl groups improved the low temperature drag reducing effectiveness but had 1ittle effect on the upper temperature limit (3).

E. Effect of Various Counter-ions on Drag Reducing Effectiveness

While a large number of counter-ions were explored, most are too costly for use in district heating or district cooling systems. Four, listed in Table 1 were of particular interest because of their effectiveness and reasonable cost $(3,6)$.

Perhaps the most versatile is salicylate which, in combination with unsaturated alky! quaternary ammonium amine salts, showed effective drag reduction over wide temperature ranges. The 3-hydroxy-2-naphthoate extended drag reduction to higher temperatures but had relatively high low temperature limits which would limit its utility in district heating systems. Tosylate, while fairly versatile, was not as effective as salicylate. Finaliy, 4-chlorobenzoic acid extended the high temperature limit beyond that of the salicylate, but also gave a high low temperature limit.

\section{F. Corrosion Effects}

Corrosion of metals commonly used in district heating and district cooling systems in contact with surfactant additives was studied (7). Pitting susceptability and corrosion rates of carbon steel, 304 stainless stee1, copper, $90 \%$ copper-10\% nickel and $60 \%$ copper-40\% zinc were measured. Exploratory efforts to find suitable corrosion inhibitors were also carried out.

In general, surfactant additives which did not contain chloride ion had no adverse effect on corrosion. The presence of chloride increased the susceptability to pitting of stainless steel in tap water. Al high temperatures, several of the corrosion inhibitors tested appeared to be compatible with representative surfactants containing chloride but only hydrazine eliminated pitting susceptability of stainless steel.

Hydrazine, while still used in the U.S., is banned in several countries as it is a suspected carcinogen. The use of deionized, deaerated water 
was at least as effective in reducing corrosion problems as the addition of corrosion inhibitors. Reduction in corrosion problems can also be accomplished by replacing chloride ion present in some surfactant additives with a more benign anion such as acetate.

G. Scale-Up of Small Tube Test Results to Larger Tubes.

Most measurements were made in 0.106 and 0.243 -inch diameter tubes. A procedure proposed by Granville (8) for scale-up of polymer drag reducing systems was used for the surfactant drag reducers. Good agreement in scale-up predictions from the 0.106 -inch tube data with measurements in the 0.243 -inch tube was obtained. Further scale-up to the data which we obtained in Argonne's 6 -inch tube also gave reasonable agreement but the assumption of equal wall shear stress could only be approximated as the small tube wall shear stresses were considerably higher than those in the 6-inch tube. We believe this scale-up procedure is satisfactory, but there are several others which should also be tested to see if even better agreement can be obtained.

H. Heat Transfer Coefficients for Friction Reducing Surfactant Solutions

Preliminary measurements of heat transfer coefficients at high temperatures (up to $120^{\circ} \mathrm{C}$ ) were made in a tube-in-tube and in a chevron plate heat exchanger (9). Heat transfer coefficients in the tube-intube exchanger were reduced as much as $90 \%$ or more at high temperatures. In the plate exchanger, the heat transfer coefficient reduction was smaller but still appreciable (10 to 50\%). Further studies of schemes to reduce the loss in heat transfer or to redesign exchangers to avoid significant reductions in heat transfer are needed.

\section{Screening Tests for Predicting Drag Reducing Effectiveness}

Rough screening was done by using a swirl test on the solutions and observing recoil. This is a qualitative measure of viscoelasticity and has proven useful but not infallible. Birefringence measurements to measure the alignment of surfactant rods believed to be necessary for drag reduction are underway. At present the results are only preliminary but there does appear to be a correlation and this test may prove valuable in screening drag reducing additives and determining effective temperature ranges.

\section{Future Plans}

The next phase of this project will focus on developing suitable cationic surfactant-counterion-corrosion inhibitor systems for (low temperature) district cooling and (high temperature) district heating systems. In addition to further advancing $F, G, H$ and I (above), a convenient separation process for removing surfactant from the solution before discharging into sewers will be developed. 


\section{References}

1. L.-C. Chou, R.N. Christensen and J.L. Zakin, "The Use of Cationis Surfactant Additives in District Heating Systems," Proc. Int. District Heating and Cooling Assoc. Conf., Vol. 28, p. 284, Baltimore, June 1987.

2. L.C. Chou, R.N. Christensen and J.L. Zakin, "Effectiveness of Drag Reducing Surfactant Additives in District Heating Systems, "Proc. Int. District Heating and Cooling Assoc. Conf., Vol. 29, p. 530, Chautauqua, NY, June 1988.

3. L.-C. Chou, "Drag Reducing Cationic Surfactant Solutions for District Heating and Cooling Systems," Ph.D. Dissertation, The Ohio State University, Columbus, 1991.

4. L.-C. Chou, R.N. Christersen and J.L. Zkain, "Drag Reducing Additives for District Cooling Systems," Proc. Int. District Heating and Cooling Assoc. Conf., Vol. 30, p. 352, Virginia Beach, June 1989.

5. L.-C. Chou and J.L. Zakin, "Use of Mixed Cations and Mixed Counter-ions to Extend the Effective Temperature Range for Drag Reducing Surfactant Additives," Proc. Int. Symp. on Fluids for District Heating, p. 75, Copenhagen, Apri1 1991.

6. L.-C. Chou, R.N. Christensen, and J.L. Zakin, "The Influence of Chemical Composition of Quaternary Ammonium Salt Cationic Surfactants on Their Drag Reducing Effectiveness," in Drag Reduction in Fluid Flow, R.H. Sellin and R.T. Moses eds., Ell is Horwood Limited Press, Chichester, West Sussex, England, p. 141, 1989.

7. B.C. Smith, B.E. Wilde and J.L. Zakin, "Corrosion Effects of Cationic' Surfactant Drag Reducing Additives on Metals Used in District Heating Systems," Proc. Int. District Heating and Cooling Assoc. Conf., Vol. 31, Toronto, June 1990.

8. Granville, P.S., "A Method for Predicting Additive Drag Reduction from Smal1 Diameter Pipe Flows," Proc. 3rd Int. Conf. on Drag Reduction, R.H.J. Sellin and R.T. Moses, eds., Univ. of Bristol, U.K., paper C3, 1984.

9. R.N. Christensen and J.L. Zakin, "Drag and Heat Transfer Reduction in Circular Tubes and Plate Fin Heat Exchangers," presented at the 82nd Annual IDHCA Meeting, San Francisco, p. 189-202 June 1991. 
Trade or Chemical Name

A. Cationic Surfactants

Arquad 12-50

Arquad 16-50

Kemamine Q-2983C

Ethoquad 0/12

Ethoquad 18/12

Ethoquad R/12-75

Kemamine EX-300

Ethoquad T/13-50

Ethoquad 0/13-50

Ethoquad R/13

HABON

DOBON

B. Counter-Ions

Sodium salicylate (Sodium 2-hydroxybenzoate)

4-ChTorobenzoic acid

p-Toluenesulfonic, acid, sodium salt (Sodium tosylate)

3-Hydroxy-2-

naphthoic acid
Supplier

Akzo Chemical co.

Akzo Chemical Co.

Witco Chemical Co.

Akzo Chemical Co.

Akzo Chemical Co.

Akzo Chemical Co.

Witco Chemical Co.

Akzo Chemical Co.

Akzo Chemical Co.

Akzo Chemical Co.

Hoechst $A G$

Hoechst $A G$

MCB Manufiscturing Chemists, Inc.

Aldrich Chemical

Company, Inc.

Aldrich Chemical

Company, Inc.

Aldrich Chemical

Company, Inc.
Chemical Structure

$\mathrm{C}_{12} \mathrm{H}_{25}-\mathrm{N}\left(\mathrm{CH}_{3}\right)_{3} \mathrm{Cl}$

$\mathrm{C}_{16} \mathrm{H}_{33^{-N}}-\mathrm{C}\left(\mathrm{CH}_{3}\right)_{3} \mathrm{Cl}$

$\mathrm{C}_{22} \mathrm{H}_{43}-\mathrm{N}\left(\mathrm{CH}_{3}\right)_{3} \mathrm{Cl}$

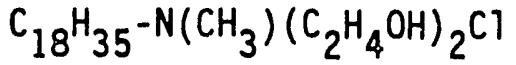

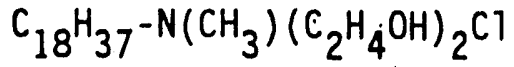

Rapeseed-N $\left(\mathrm{CH}_{3}\right)\left(\mathrm{C}_{2} \mathrm{H}_{4} \mathrm{OH}\right)_{2} \mathrm{Cl}$

$\mathrm{C}_{22} \mathrm{H}_{43}-\mathrm{N}\left(\mathrm{CH}_{3}\right)\left(\mathrm{C}_{2} \mathrm{H}_{4} \mathrm{OH}\right)_{2} \mathrm{Cl}$

Tallow-N $\left(\mathrm{C}_{2} \mathrm{H}_{4} \mathrm{OH}\right)_{3} \mathrm{AC}$

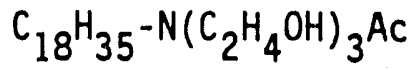

Rapeseed-N $\left(\mathrm{C}_{2} \mathrm{H}_{4} \mathrm{OH}\right)_{3} \mathrm{AC}$

$\mathrm{C}_{16} \mathrm{H}_{33}-\mathrm{N}\left(\mathrm{CH}_{3}\right)_{3}(3-\mathrm{OH}-2-$

naphthoate)

$\mathrm{C}_{22} \mathrm{H}_{45}-\mathrm{N}\left(\mathrm{CH}_{3}\right)_{3}(3-\mathrm{OH}-2-$ naphthoate)

$2-(\mathrm{OH}) \mathrm{C}_{6} \mathrm{H}_{4}-\mathrm{COO}^{-} \mathrm{Na}^{+}$

$4-(\mathrm{Cl}) \mathrm{C}_{6} \mathrm{H}_{4}-\mathrm{COO}^{-} \mathrm{H}^{+}$

$4-\left(\mathrm{CH}_{3}\right) \mathrm{C}_{6} \mathrm{H}_{4}-\mathrm{SO}_{3}{ }^{-} \mathrm{H}^{+}$

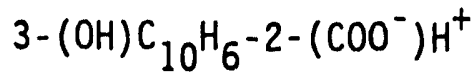




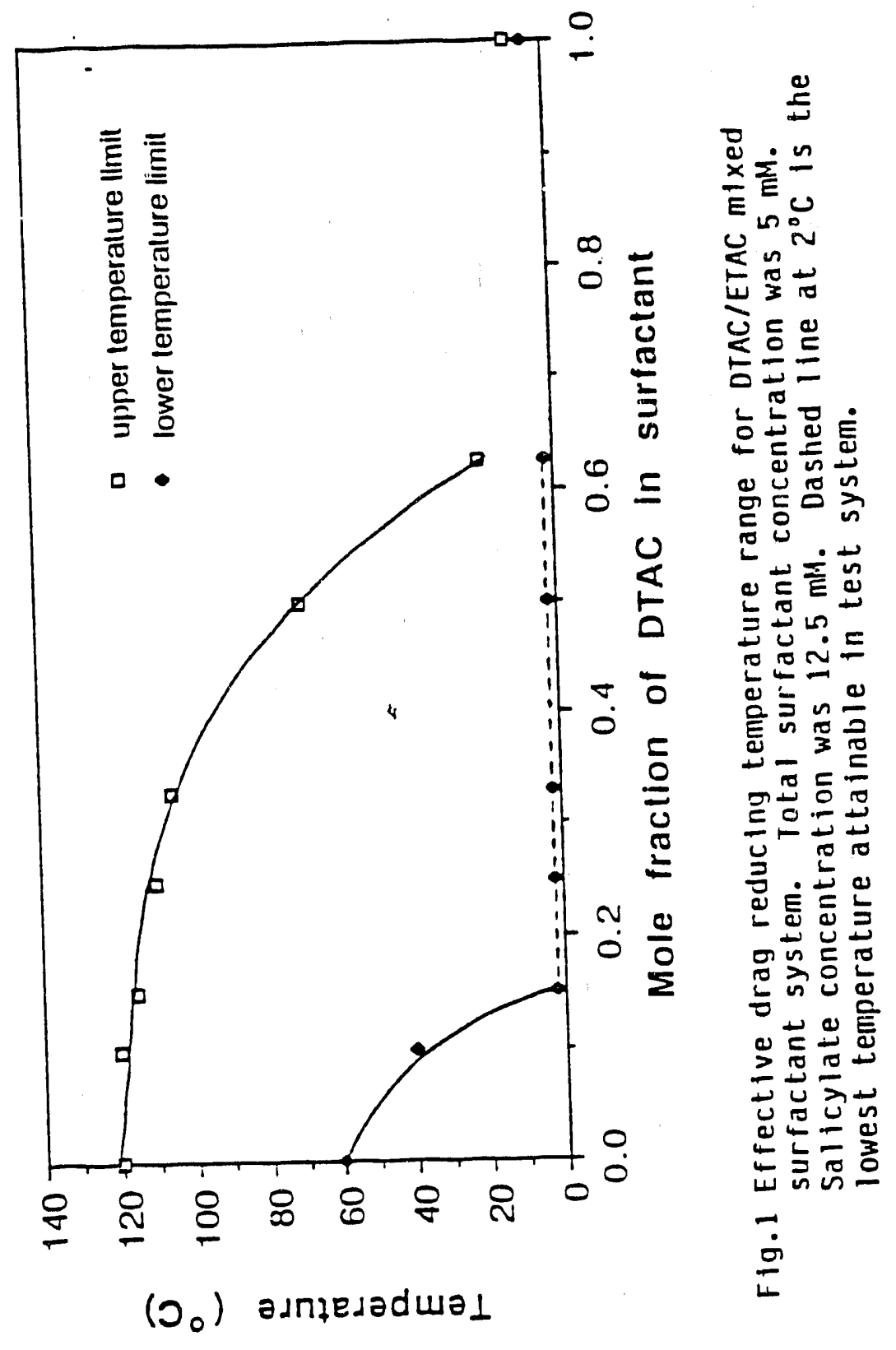




\section{Personnel Involved}

PI - Professor Jacques L. Zakin, Department of Chemical Engineering

Co-PI - Professor Richard N. Christensen, Department of Mechanical Engineering

Dr. Deborah Stutman-Brickey, Visiting Assistant National Science Foundation Woman Professor, Department of Chemical Engineering.

Dr. Steve Choi, Argonne National Laboratory.

Lu-Chien Chou, Ph.D. candidate, Department of Chemical Engineering

Bin Lu, Ph.D. candidate, Department of Chemical Engineering

Bryan C. Smith, Ph.D. candidate, Department of Chemical Engineering

Marleen Murphy, M.S. candidate, Department of Chemical Engineering

Dan Franke, B.S. candidate, Department of Chemical Engineering

Paul Jacyk, B.S. candidate, Department of Chemical Engineering

A. Singh, M.S. candidate, Department of Mechanical Engineering

Michael Kukla, Design Engineer, Department of Chemical Engineering

Roy A. Renshaw, Instrument Maker, Department of Chemical Engineering 
